\title{
A Summary of Revisions Applied to a Turbulence Response Analysis Method for Flexible Aircraft Configurations
}

\author{
Christie J. Funk ${ }^{*}$, Boyd Perry, III ${ }^{\dagger}$, Walter A. Silva* \\ NASA Langley Research Center, Hampton, Virginia, 23681 \\ Brett Newman ${ }^{\S}$ \\ Old Dominion University, Norfolk, Virginia, 23529
}

\begin{abstract}
A software program and associated methodology to study gust loading on aircraft exists for a classification of geometrically simplified flexible configurations. This program consists of a simple aircraft response model with two rigid and three flexible symmetric degrees-of freedom and allows for the calculation of various airplane responses due to a discrete oneminus-cosine gust as well as continuous turbulence. Simplifications, assumptions, and opportunities for potential improvements pertaining to the existing software program are first identified, then a revised version of the original software tool is developed with improved methodology to include more complex geometries, additional excitation cases, and additional output data so as to provide a more useful and precise tool for gust load analysis. In order to improve the original software program to enhance usefulness, a wing control surface and horizontal tail control surface is added, an extended application of the discrete one-minus-cosine gust input is employed, a supplemental continuous turbulence spectrum is implemented, and a capability to animate the total vehicle deformation response to gust inputs is included. These revisions and enhancements are implemented and an analysis of the results is used to validate the modifications.
\end{abstract}

\section{Nomenclature}

$\begin{array}{ll}C & =\text { generalized damping matrix } \\ C & =\text { chord, } \mathrm{m} \\ f & =\text { frequency, hertz } \\ K & =\text { generalized stiffness matrix } \\ L & =\text { scale of turbulence, } \mathrm{m} \\ l_{w} & =\text { length of wing elastic axis, } \mathrm{m} \\ M & =\text { generalized mass matrix } \\ \mathrm{Q} & =\text { generalized force matrix } \\ T & =\text { kinetic energy } \\ U & =\text { elastic energy } \\ V & =\text { velocity, m/s } \\ w_{g} & =\text { vertical gust velocity, } \mathrm{m} / \mathrm{s} \\ x_{t} & =\text { tail length, m } \\ \alpha & =\text { angle of attack, rad } \\ \frac{d \varepsilon}{d \alpha} & =\text { downwash coefficient } \\ \omega & =\text { circular frequency, rad/s } \\ \xi & =\text { generalized coordinate }\end{array}$

\footnotetext{
${ }^{*}$ Research Aerospace Engineer, Aeroelasticity Branch, AIAA Member.

${ }^{\dagger}$ Distinguished Research Associate, Aeroelasticity Branch, AIAA Senior Member.

* Senior Research Scientist, Aeroelasticity Branch, AIAA Associate Fellow.

${ }^{\S}$ Professor, Department of Mechanical and Aerospace Engineering, AIAA Associate Fellow.
} 


\section{Introduction}

$\mathrm{C}$ ontinuous efforts to advance technologies and design more sophisticated aircraft have been made since Wilbur and Orville Wright's first successful flight in 1903. With such advancements, aircraft evolved into larger, more flexible, increasingly complex vehicles that could travel farther, at higher altitudes, and at faster speeds. As the evolution in aircraft design progressed, the need arose to also improve techniques for analyzing the characteristic behaviors of aircraft. One significant area of consideration is given to the response of aircraft to the turbulent atmospheric flight environment. Within this area of study, consideration is given to both the response of the aircraft to a discrete gust encounter and to the response of the aircraft to continuous turbulence. As aircraft design evolved, the methods utilized to study the behavior of aircraft in turbulent air also progressed.

With the engineering goal of designing and operating aircraft safely, reliable methods of determining gust loads are required. Since the first National Advisory Committee for Aeronautics (NACA) publication relating to gust loads was written in 1915, the scope of gust analysis procedures has progressed from discrete time-domain analysis methods to continuous frequency-domain analysis via Power-Spectral Density (PSD) methods. In chronological order, the following gust analysis methods were introduced: 1) Sharp-Edged Gust Formula; 2) Ramp Gradient Gust Formula; 3) Triangular Gradient Shape Gust; 4) Revised Gust Formula (Pratt's Method); and 5) Power-Spectral Density Analysis. ${ }^{1}$ Pratt's method assumes a one-minus-cosine discrete gust profile while the PSD approach assumes that the turbulence is a Gaussian random process and allows for study over the entire frequency range for which response values are needed while covering multiple degrees-of-freedom. While the FAA certification requirements include only those associated with continuous turbulence, discrete gust load analysis methods are still considered useful in providing insight to aircraft behaviors in response to a turbulent atmosphere and may be used as an alternate means of compliance.

In a 1997 paper titled "A MATLAB Program to Study Gust Loading on a Simple Aircraft Model," a program to study aircraft loading due to discrete gusts and continuous turbulence was published. ${ }^{2}$ While this software program enables the calculation of five output load quantities due to discrete gusts as well as continuous turbulence, the five degree-of-freedom half aircraft model is limited to simple geometries. The following geometric and structural parameter variations are permitted: 1) aircraft wing area and horizontal tail area; 2) aircraft wing sweep angle; 3) tail semispan; 4) aircraft center of gravity position; and 5) aircraft main mass properties. While the aircraft wing area is variable, the restriction exists that the wing root chord and wing tip chord must be equal. For reference, the structural model is shown in Fig. 1. Note in Fig. 1 that the aircraft configuration is defined by five invariable mass points along the swept-back aircraft wing, ten invariable fuselage mass points, and one invariable mass point on the unswept, untapered horizontal tail, thereby limiting the complexity of the structural configuration and unrealistically limiting the possible planform geometries.

In order to modify the original program to enhance its usefulness, the capability to include more complex, userdefined geometries is implemented, a wing control surface and horizontal tail control surface are added, an extended application of the discrete one-minus-cosine gust input is employed, a supplemental continuous turbulence power spectrum is included, and a capability to animate the total vehicle physical deformation response to gust inputs is provided.

The paper begins with a brief description of the original software program and its associated methodology. Improvements and enhancements are then discussed, followed by results and concluding remarks.

\section{Original Gust Response Model Program}

\section{A. Aircraft Model Configuration and Mode Shapes}

The original two-dimensional half-aircraft response model consists of a beam-model fuselage, a swept, rectangular wing, and an unswept, rectangular horizontal tail. ${ }^{2}$ The original structural model is defined by five wing mass points, one tail mass point, and ten fuselage mass points with a right-handed axis system having its origin situated at the intersection of the spanwise extension of the leading edge of the Mean Aerodynamic Chord (MAC) and the aircraft centerline. The global $\mathrm{x}$-axis is aligned with the vehicle centerline and is defined as positive forward; the global y-axis is defined to be positive moving in the outboard direction along the right wing; and the global zaxis is defined as positive downward. The original aircraft structural model, including the position of the center of gravity, is shown in Fig. 1. A local stability axis system lies along the wing elastic axis and is denoted as x' and $y^{\prime}$ in Fig. 1.

Two rigid body modes and three flexible modes are included in the gust response model program. The rigid body displacement modes are defined by a translational motion in the z-direction, known as plunge, and a rotation about the y-axis, known as pitch. Translational motion in the x-direction is not considered. The plunge mode, mode 1 , is 
positive in the direction of the positive z-axis and the pitch mode, mode 2, is defined by a positive nose up rotation about the y-axis.

The flexibility of the airplane is assumed to be sufficiently well captured by two wing modes $\left(1^{\text {st }}\right.$ bending and $1^{\text {st }}$ torsion) and one rear fuselage mode ( $1^{\text {st }}$ bending). Rear fuselage bending and wing bending deflections are positive in the direction of the positive z-axis, and wing torsion is positive leading edge up. The elastic deformation modes are given as simple mathematical expressions describing the deformation curve rather than being associated with a set of eigenmodes. Illustrations of one rigid body mode and one flexible mode are given in Figs. 2 and 3, respectively.

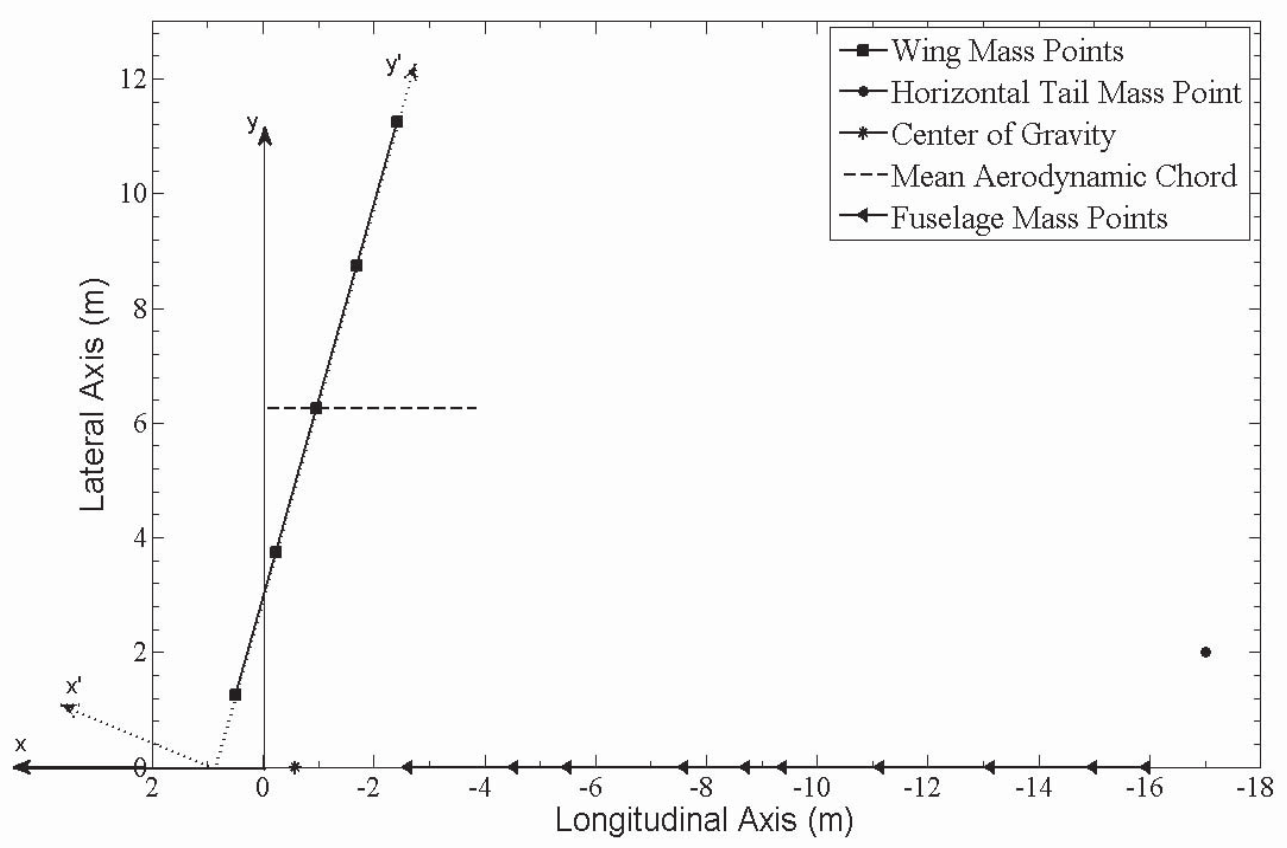

Figure 1. Original Configuration Structural Beam Model

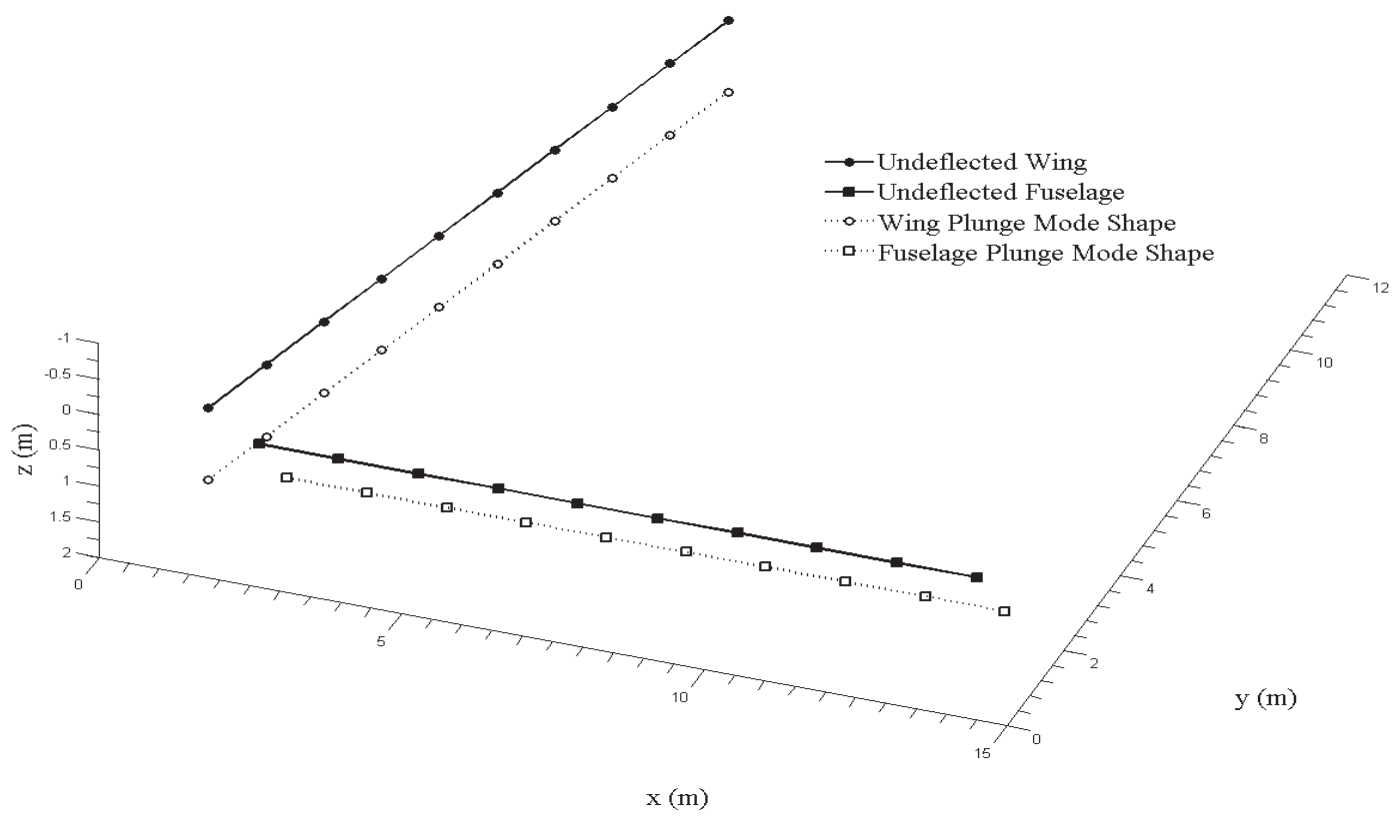

Figure 2. Plunge Mode

American Institute of Aeronautics and Astronautics 


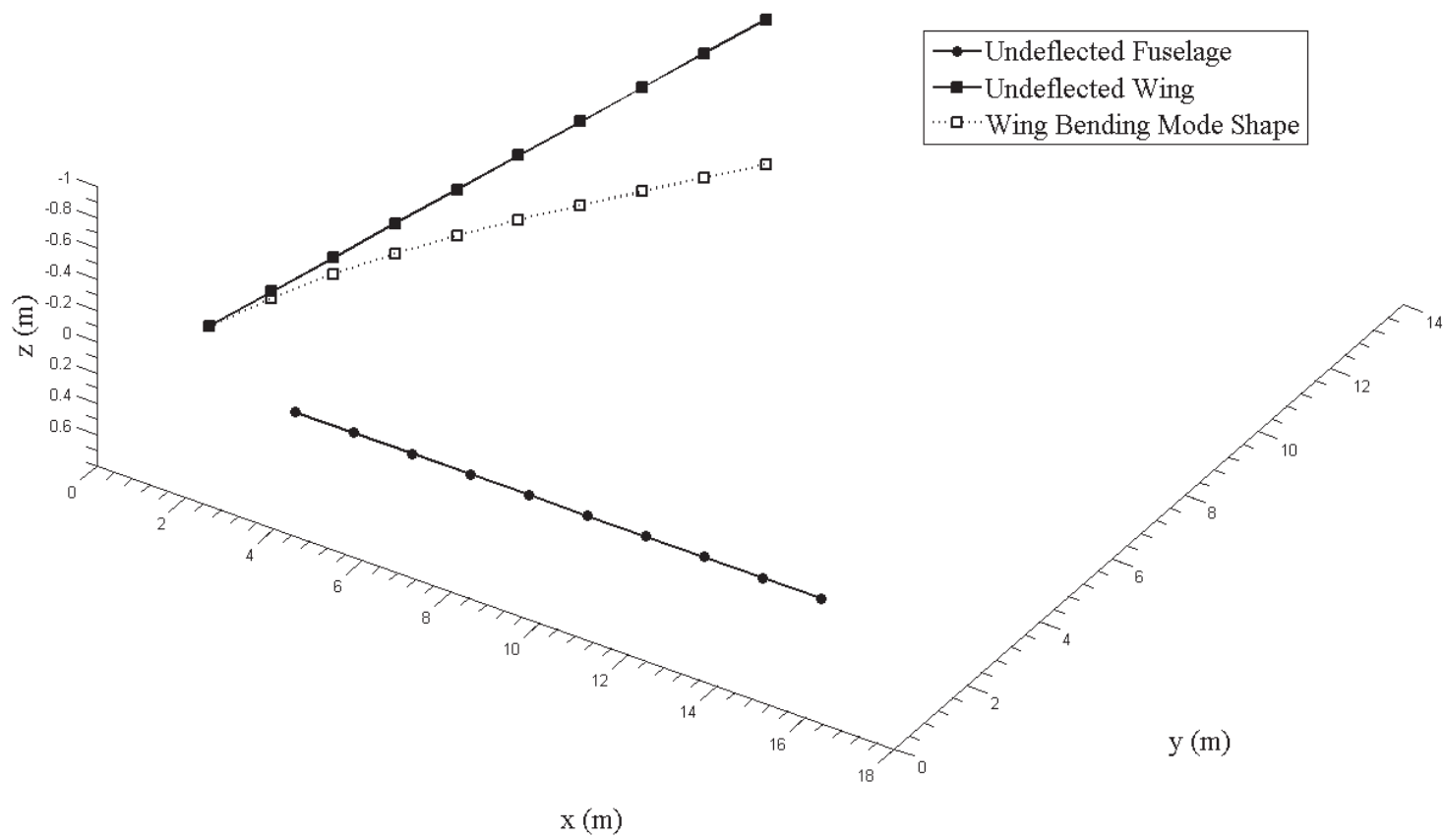

Figure 3. Wing Bending Mode

\section{B. Mathematical Approach, Inputs, and Output Load Responses}

A convenient approach to determining the equations of motion for systems with multiple degrees-of-freedom is available due to J.L. Lagrange. ${ }^{3}$ Derivation of the Lagrange equation is not presented in this paper; however, an explicit derivation of this equation is presented in Refs. 3 and 4. For many problems in aeroelasticity, the use of Lagrange's equation reduces the complexity of the mathematics involved in deriving the equations of motion by eliminating the dependent Cartesian coordinates and introducing independent variables known as generalized coordinates. ${ }^{4}$ The generalized coordinates implicitly contain the constraints on the motion of the system. By transformation of the variables from a Cartesian coordinate system to generalized coordinates, the equations of motion can be transformed into the form of the Lagrange equation. The Lagrange equation is expressed as

$$
\frac{d}{d t}\left[\frac{\partial T}{\partial \dot{\xi}}\right]-\frac{\partial T}{\partial \xi}+\frac{\partial U}{\partial \xi}=Q
$$

For simplicity, time-domain solution procedures are carried out in the frequency-domain via Fourier transforms rather than in the time-domain with direct integration; therefore, this program is only appropriate for studying the responses of linear systems. Processing of the Lagrange equation results in a set of $n$ second order governing equations of motion of the form

$$
M \ddot{\vec{\xi}}+C \dot{\vec{\xi}}+K \vec{\xi}=Q_{r} \vec{\xi}+Q_{w} w_{g}
$$

Solution of the equations of motion expressed in generalized coordinates becomes

$$
\vec{\xi}=A^{-1} Q_{w} w_{g}
$$

where

$$
A=-\omega^{2} M+i \omega C+K-Q_{r}
$$

The aerodynamic forces and moments are computed using simple strip theory. In the original program, the aircraft wing is divided into five equal strips with a constant wing lift curve slope along the wing span and the 
horizontal tail is represented by one strip with a constant tail lift curve slope along the tail span. The unsteady aerodynamic force acting on a thin airfoil undergoing unsteady motion was obtained by Herbert Wagner, Hans Küssner, Theodore Theodorsen, William Sears, and others. ${ }^{4}$ In this work unsteady effects are accounted for by applying Theodorsen's function to the aircraft response-induced angle of attack, $\alpha_{w}$, and by applying Sears' function to the gust induced angle of attack, $\alpha_{g}$. A cogent derivation of these functions is given in Ref. 4.

Excitation approaches include a discrete one-minus-cosine shaped gust and the von Kármán continuous turbulence power spectrum. An illustration of the one-minus-cosine shaped gust input is shown in Fig. 4. The five available output load quantities are: 1) center of gravity acceleration (load factor); 2) wing root bending moment; 3 ) wing root shear force; 4) wing root torsion moment; and 5) tail root shear force. Assuming that each output load can be expressed as a linear function of the input load and generalized coordinates, the output load $\vec{y}$ can be written as

$$
\vec{y}=C \vec{\xi}+D w_{g}
$$

Substituting Eq. (3) into Eq. (5) yields

$$
\vec{y}=\left(C A^{-1} Q_{w}+D\right) w_{g}
$$

Setting

$$
H=C A^{-1} Q_{w}+D
$$

the output load equation becomes

$$
\vec{y}=H w_{g}
$$

where $H$ is the transfer matrix. Given $H$, the outputs due to the inputs can now be determined. An example of the five output time histories due to a discrete one-minus-cosine gust input is given in Fig. 4. All responses correspond to the structural configuration shown in Fig. 1 with default flight conditions. The default aircraft dimensions and main mass properties for this configuration can be found in Ref. 2. For convenience, default flight conditions are given in Table 1. The time histories in Fig. 4 exhibit three important characteristics. First, for all quantities, the initial response correlated very closely with the 0.4 second duration and shape of the one-minus-cosine gust input. Second, for all quantities, following the initial response, the presence of a low frequency $(0.5 \mathrm{~Hz})$ response corresponding to the vehicle short-period mode is observed. Third, visible primarily in wing shear force and bending moment, following the initial response and superimposed on the low-frequency response, the presence of a higher frequency response $(2.9 \mathrm{~Hz})$, corresponding to the wing bending mode, is observed.

Table 1. Aerodynamic Properties and Flight Conditions

\begin{tabular}{|l|l|}
\hline Property & Value \\
\hline & \\
\hline Section Wing Lift Curve Slope & $-6.379 / \mathrm{rad}$ \\
\hline Section Tail Lift Curve Slope & $-4.61 / \mathrm{rad}$ \\
\hline Downwash Coefficient & 0.35 \\
\hline Fuselage Moment Coefficient & 0.40 \\
\hline Aircraft True Airspeed & $220 \mathrm{~m} / \mathrm{s}$ \\
\hline Altitude & $7000 \mathrm{~m}$ \\
\hline Air Density & $0.59 \mathrm{~kg} / \mathrm{m}^{3}$ \\
\hline
\end{tabular}



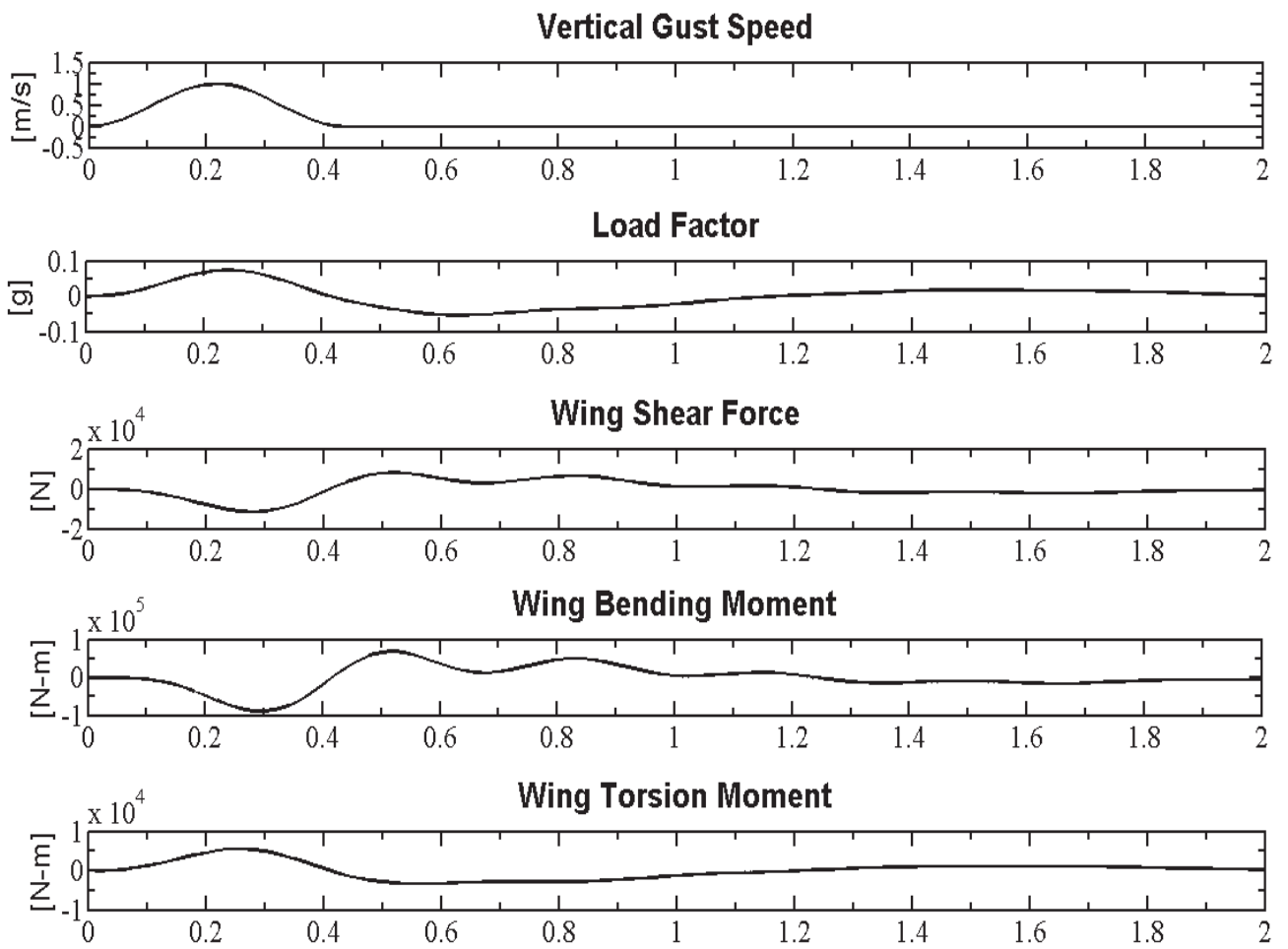

Tail Shear Force

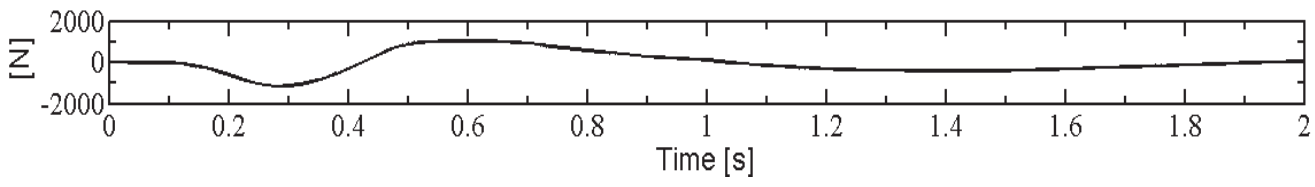

Figure 4. Time Responses due to One-Minus-Cosine Discrete Gust Input

\section{Program Methodology Revisions and Enhancements}

The objective of this work was to modify the original program developed in Ref. 2 to include enhancements that improve its utility. A brief discussion of the modification procedures and implemented enhancements is given in this section.

\section{A. Modification of Structural Beam Model}

The expansion of the existing structural parameters to include implementation of a variable number of mass points on the aircraft wing, fuselage, and horizontal tail; additional options for mass, inertia, and bending and torsional stiffness distributions; implementation of a variable aircraft wing and horizontal tail taper ratio; and implementation of a variable horizontal tail sweep angle is discussed in this section. Additionally, the revised structural model is developed in a modified axis system. These modifications improve the gust response model presented in Ref. 2 by creating additional user-defined parameters and by eliminating certain program limitations to allow for the inclusion of more complex geometries.

Development of the aircraft model to include more complex geometries requires the capability for implementation of a swept-back, tapered aircraft wing and a swept-back, tapered horizontal tail. This feature has been added to allow for user-defined sweep angles and taper ratios. In order to develop a more precise structural model for analysis of gust loads, it is useful to be able to vary the number of mass points along the span of the aircraft wing and horizontal tail and along the length of the fuselage. Recall that computation of the aerodynamic forces and moments is accomplished utilizing simple strip theory aerodynamics; therefore, because there is one 
lumped mass per designated strip $i, n$ desired mass points equates to $n$ number of strips chosen by the user for the aerodynamic model. When executing the program, the user is prompted to input the desired number of strips for the model, thus simultaneously defining $n$ number of mass points along the aircraft wing, horizontal tail, and fuselage. The location of mass lump $i$ is consistent for each strip in the three fundamental elements comprising the aircraft model. All strips are of equal width along the span of the respective component; consequently, each lumped mass is equally spaced along the span of the aircraft wing and horizontal tail and along the length of the fuselage. A revised structural beam model example comprised of twenty aircraft wing, horizontal tail, and fuselage lumped masses is shown in Fig. 5 in a new global axis system. The illustrated configuration mentioned above contains a planform identical to Fig. 1 but employs the previously described modifications, thus creating a structural model that is more representative of the vehicle.

In addition to the structural model modifications, a useful feature is to provide options for the manner in which masses and inertias are distributed along the aircraft components. The following distribution options are available to the user: 1) default linear distribution; 2) user-defined mass and inertia values per strip; and 3) user-defined distribution factors. The default distribution is linear and associated default distribution factors are used to compute the mass and inertia values for each respective strip. The second distribution option allows the user to manually define mass and inertia values for each strip. The third option allows the user to define desired distribution factors for each strip. From the user-defined distribution factors, given the total component mass and inertia values, the respective strip values for mass and inertia are computed in the same manner as for option 1.

Similar to the added features for lumped mass and inertia distributions, bending stiffness, EI, and torsional stiffness, GJ, distribution options are also implemented. A wing element has a constant bending stiffness and a constant torsional stiffness, a fuselage element has only a constant bending stiffness and is assumed to be torsionally rigid, and a tail element is considered to be rigid. Evaluation of the default linear distribution for fuselage bending stiffness found the distribution to be reasonable; therefore, the fuselage bending stiffness distribution options follow those given for the lumped mass and inertia distributions. While a linear stiffness distribution provides an adequate approximation for the aircraft wing, this distribution does not yield the most reasonable fit to the original model from Ref. 2. Therefore, an additional, more accurate approximation is employed. This alternate option utilizes a cubic spline interpolation method to determine the stiffness distribution along the aircraft wing. A requirement for this option is that the user defines EI and GJ values for lumped masses at $10 \%, 30 \%, 50 \%, 70 \%$, and $90 \%$ semispan. Interpolation is then performed to obtain the EI and GJ values at the remaining lumped mass locations. An example wing bending stiffness distribution resulting from the cubic spline interpolation method given an aircraft wing comprised of ten lumped mass points is given in Fig. 6. This distribution is plotted over the original distribution found in Ref. 2 and illustrates accurate agreement between the two implementations.

For user convenience, a new global axis system was desired. This new axis system is right-handed and has its positive $\mathrm{x}$-axis pointing aft and its positive z-axis pointing up. The origin of this new axis system is located at the intersection of the wing leading edge with the fuselage centerline. Therefore, for all straight and aft-swept wings (and even for some forward-swept wings), the origin of the new axis system is forward of the origin of the original axis system. Expressed in the original global axis system, the longitudinal offset of the origin of the new global axis system from the origin of the original global axis system is

$$
x_{o}=y_{M A C} \tan \Lambda
$$

where $y_{M A C}$ is the y-location of the leading edge of the MAC and $\Lambda$ is the sweep angle of the leading edge of the wing. The transformation equations are given as

$$
\left\{\begin{array}{l}
x_{\text {new }} \\
y_{\text {new }} \\
z_{\text {new }}
\end{array}\right\}=\left[\begin{array}{ccc}
-1 & 0 & 0 \\
0 & 1 & 0 \\
0 & 0 & -1
\end{array}\right]\left\{\begin{array}{c}
x_{\text {orig }} \\
y_{\text {orig }} \\
z_{\text {orig }}
\end{array}\right\}+\left\{\begin{array}{c}
x_{o} \\
0 \\
0
\end{array}\right\}
$$

An illustration of the original and new axes systems is given in Fig. 7. 


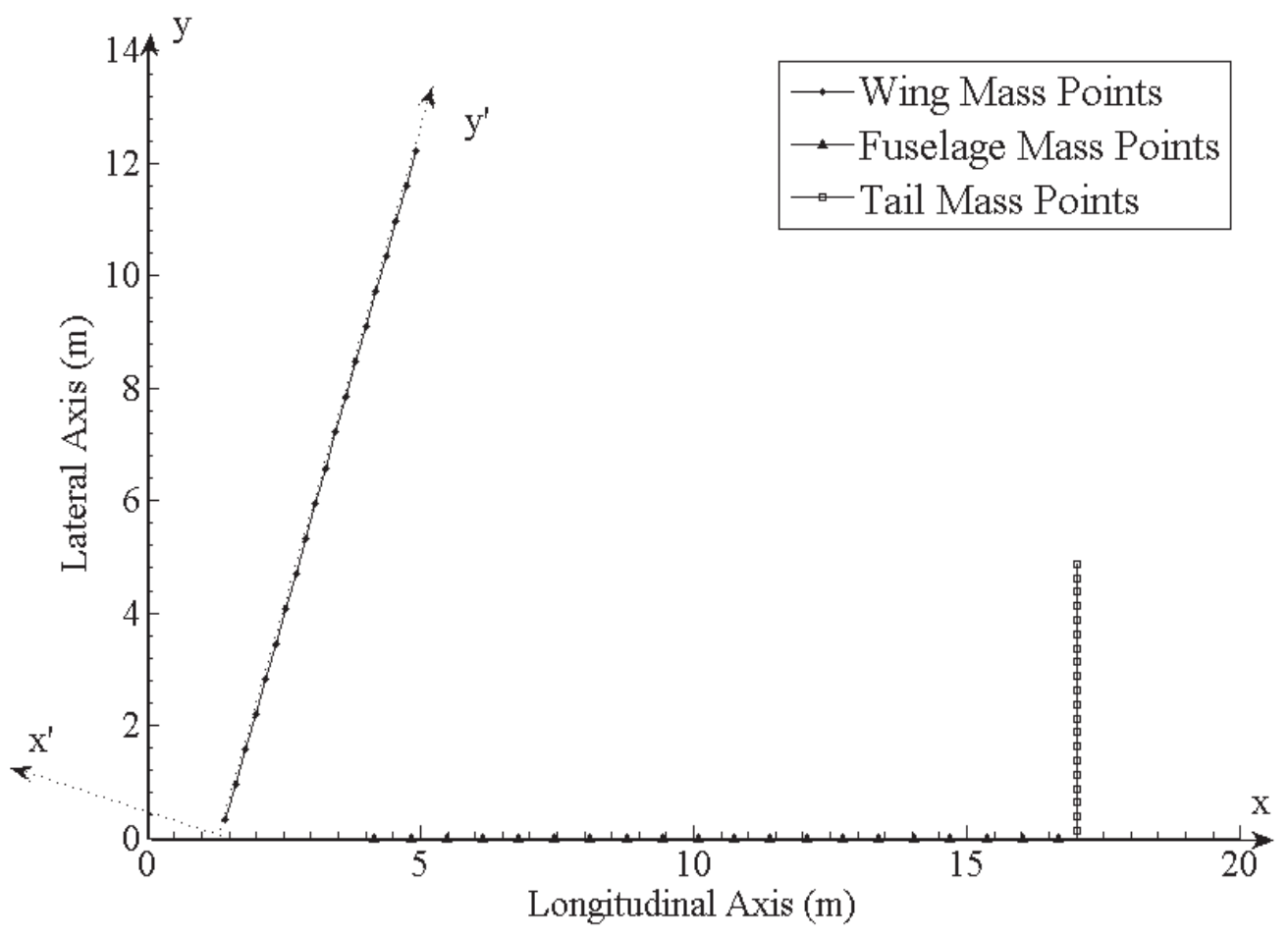

Figure 5. Modified Structural Beam Model

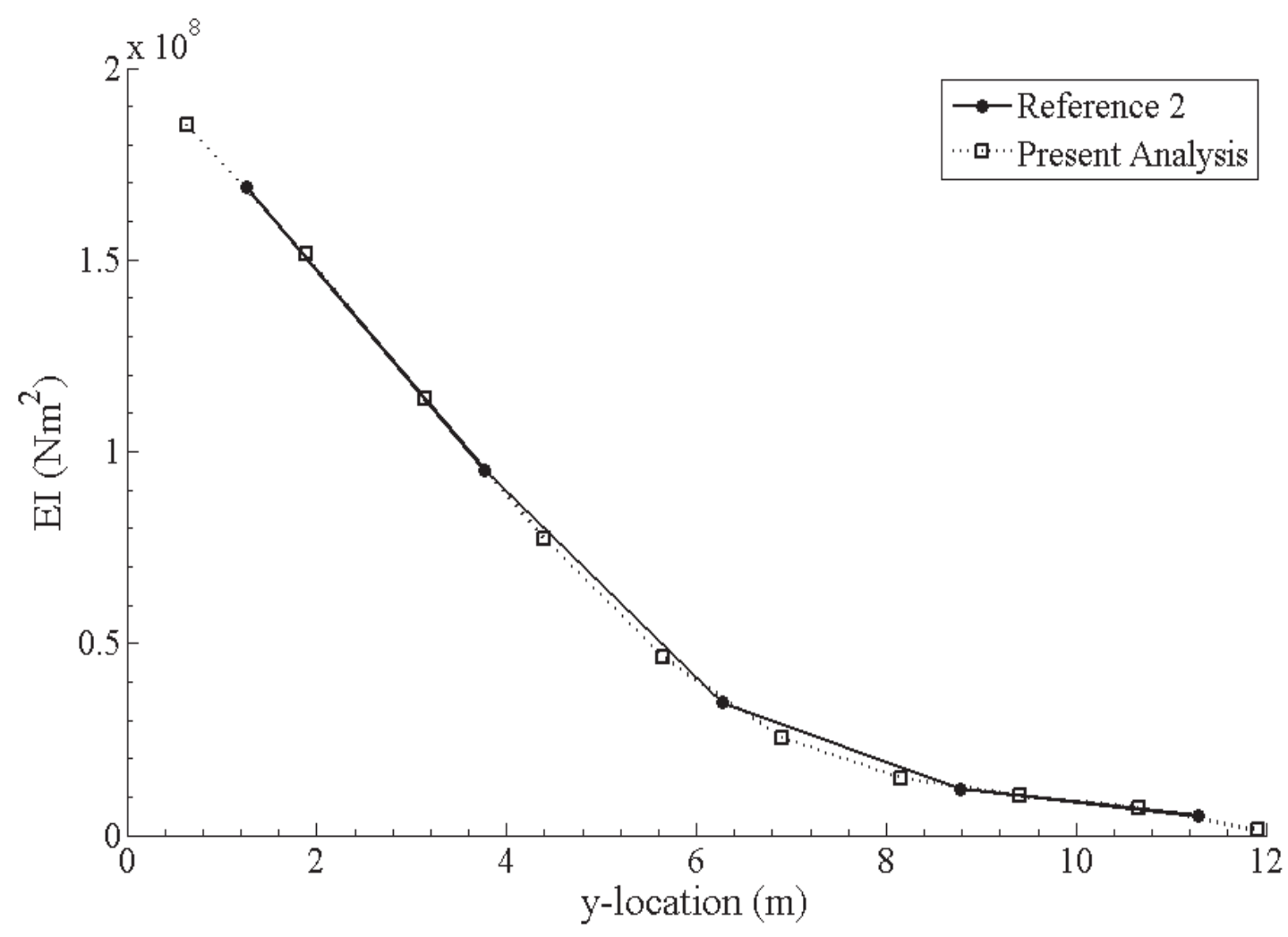

Figure 6. Wing Bending Stiffness Distribution

American Institute of Aeronautics and Astronautics 


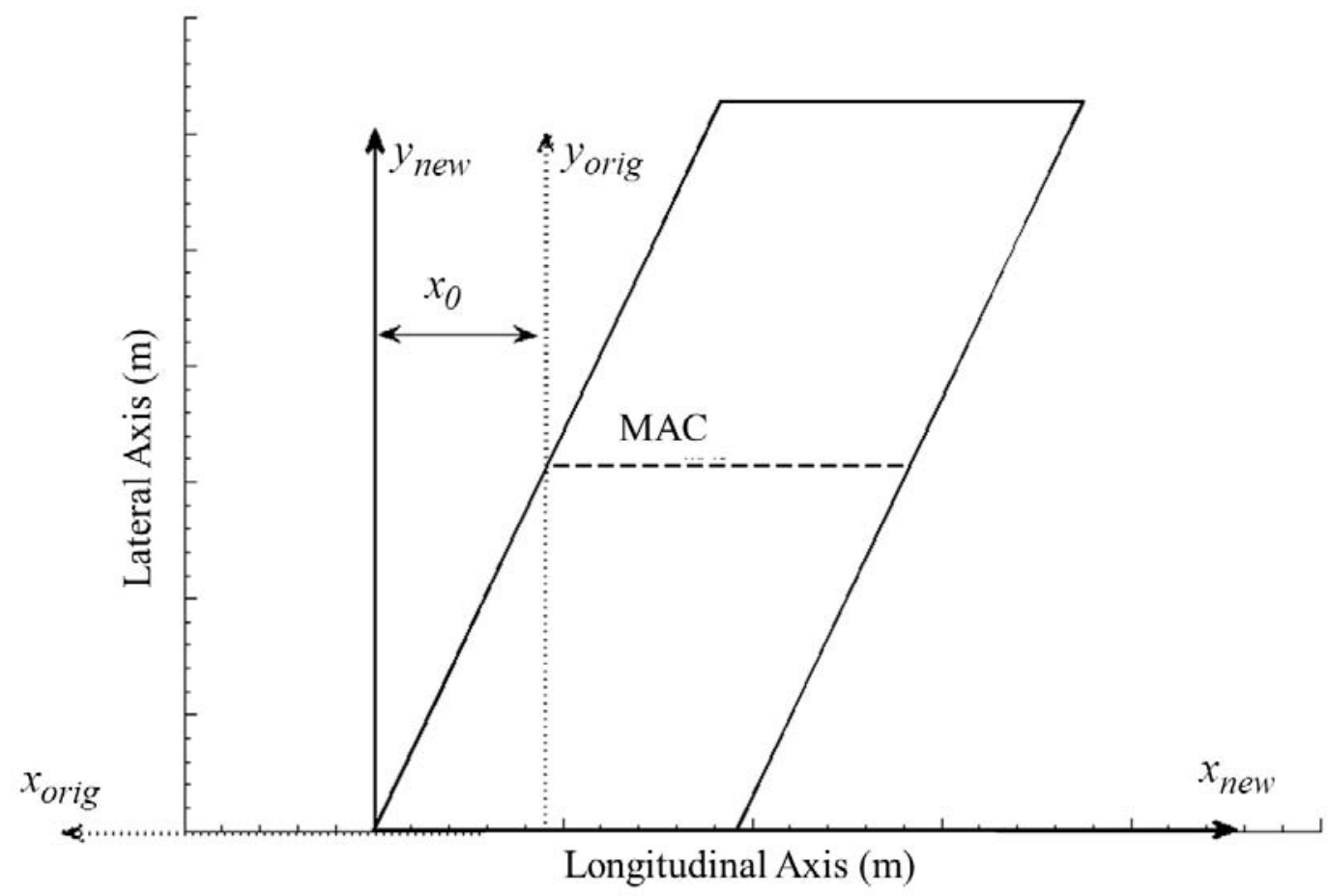

Figure 7. Illustration of Original and New Axes Systems

\section{B. Modification of Aerodynamic Strip Model}

It is beneficial to permit the user to define an aerodynamic model comprised of a variable number of strips. The procedure implemented in the development of the revised aerodynamic strip model generates an aerodynamic model comprised of a user-defined equal number of strips along the aircraft wing, horizontal tail, and fuselage. An example illustration of a fifty-strip configuration is provided in Fig. 8. As a result of the improvement applied to the generation of the aerodynamic model, it is necessary to modify the respective lift and moment equations to reflect the user-defined number of strips. Additionally, because the original wing is untapered, the average chord of each strip is equal to the MAC; however, the average chord of each strip varies as a result of the modified tapered configuration. As shown in Fig. 9, for a wing with $n$ strips there are $n+1$ boundaries. For the $i^{\text {th }}$ strip, the inboard and outboard boundaries have chord lengths $c_{i}$ and $c_{i+1}$, respectively. Therefore, the average chord for the $i^{\text {th }}$ strip is given by

$$
c_{w_{i}}=\frac{\left(c_{i}+c_{i+1}\right)}{2}
$$

and the lift and moment equations are then solved using the average chord of each strip. Computation of the horizontal tail average chord per strip follows Eq. (11). Likewise, the lift force acting on the horizontal tail is calculated using the average chord per tail strip. A difference exists when accounting for the decrease in horizontal tail angle of attack produced by the downwash angle. In the original configuration, the downwash angle was computed with reference to the second wing strip. For the five-strip original configuration, the y-location of the outboard boundary of the second wing strip is equal to the horizontal tail quarter-span. Given a modified variablestrip aerodynamic framework, model inaccuracy is introduced if consistent use of the second wing strip as a reference point when computing the downwash angle is employed, as the y-location of the outboard boundary of the second wing strip fluctuates with number of strips. Rather, a minimum difference approach is employed to identify the strip that retains an outer boundary $y$-value nearest to the quarter-span of the horizontal tail. Computation of the tail downwash angle, $\alpha_{t_{\text {down }}}$, at time $t^{\prime} \equiv t-\frac{l_{t}}{\mathrm{~V}}$, is given as

American Institute of Aeronautics and Astronautics 


$$
\alpha_{t_{\text {down }}}=\frac{d \varepsilon}{d \alpha}\left(\alpha_{w_{r}}+\alpha_{g_{r}}\right)_{t^{\prime}}
$$

where $l_{t}$ is the distance from the wing reference strip to the swept tail and the sub-subscript $r$ denotes the reference strip number previously discussed.

In summary, while simple strip theory aerodynamics is applied to the gust response model, better utility is achieved by employing an aerodynamic model comprised of a user-defined number of strips. As a result of introducing a variable aerodynamic strip model, the force and moment equations are modified accordingly.

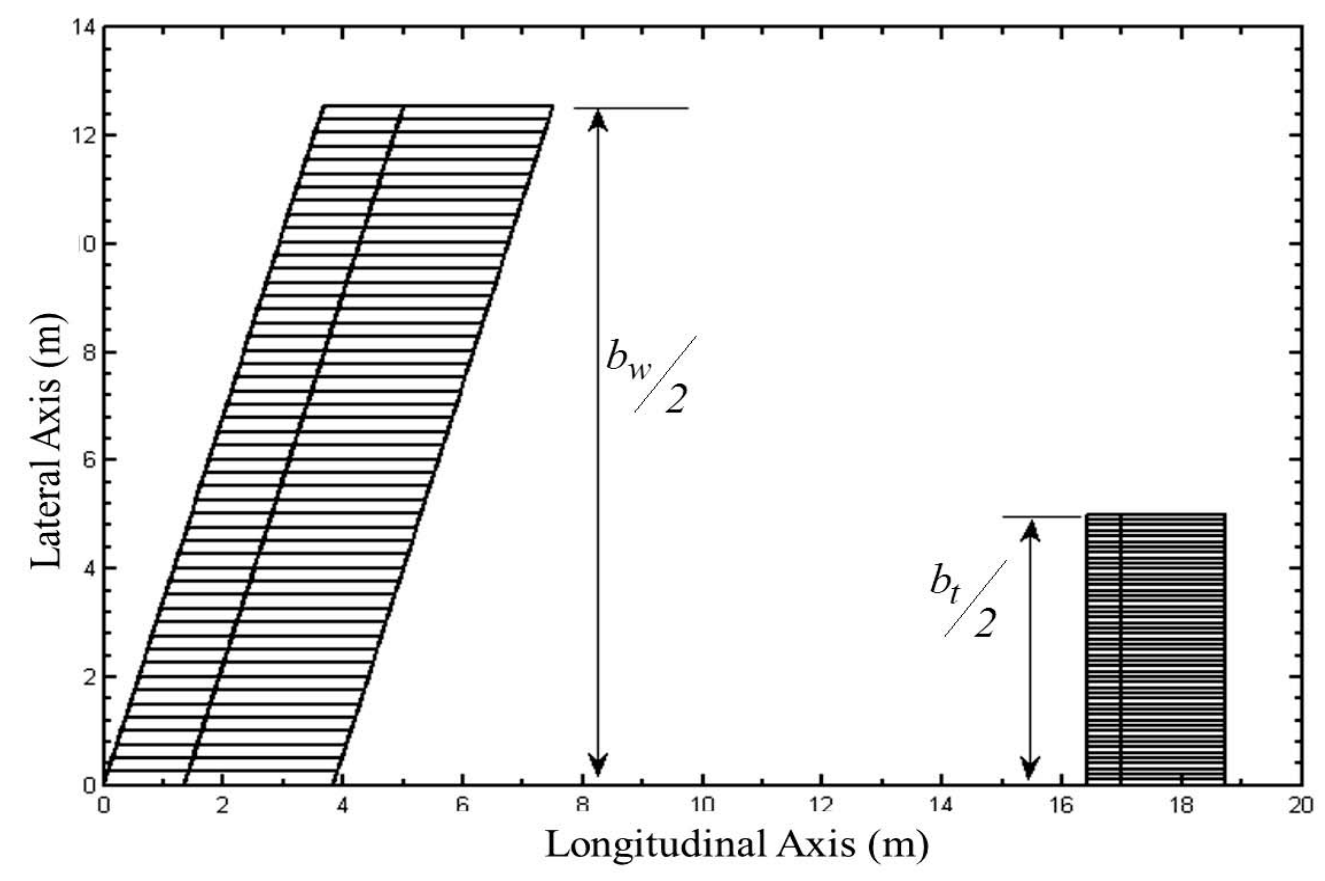

Figure 8. Illustration of Enhanced Aerodynamic Strip Model

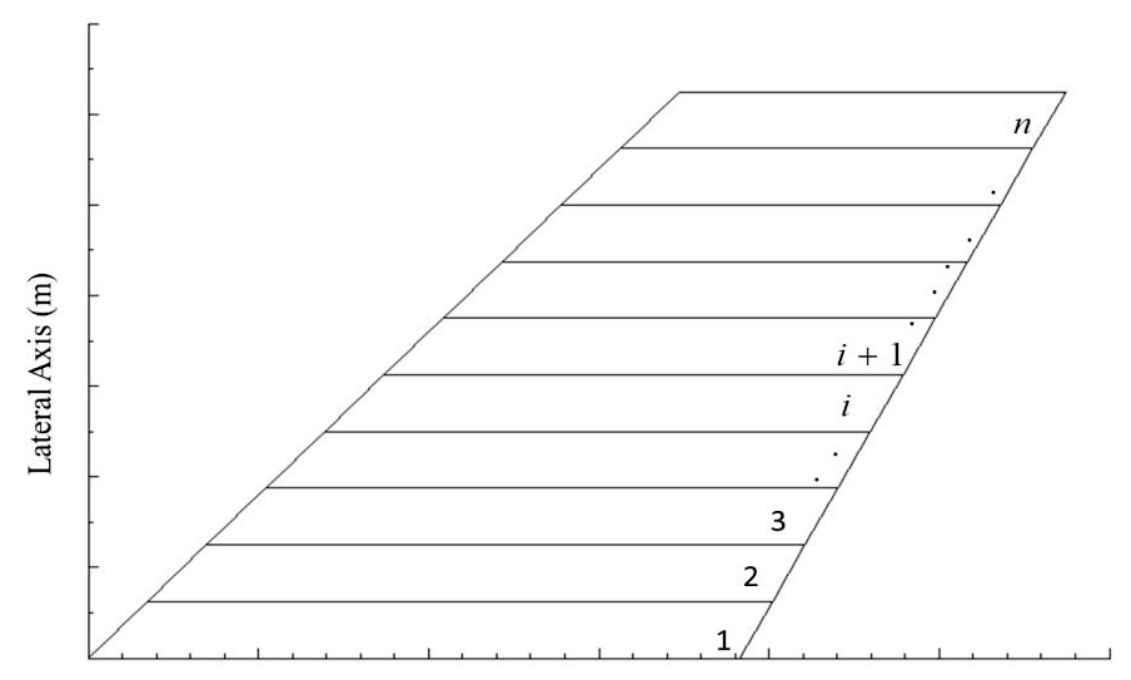

Longitudinal Axis (m)

Figure 9. Wing Strip Boundaries

American Institute of Aeronautics and Astronautics 


\section{Extended Applications of Gust Inputs}

For completeness, a second continuous PSD function, given by Hugh Dryden, is added. Additionally, an extended application of the one-minus-cosine gust input is employed. The rational one-sided Dryden PSD function is expressed in the frequency-domain as ${ }^{5}$

$$
\Phi_{w}(f)=\frac{2 L\left(1+3\left(\frac{2 \pi L}{V} f\right)^{2}\right)}{V\left(1+\left(\frac{2 \pi L}{V} f\right)^{2}\right)^{2}}
$$

A comparison of the von Kármán and Dryden PSDs shows that logarithmic plots of these spectra share similar shapes and have the same low-frequency asymptotes; however, at the high frequencies, the Dryden spectrum attenuates with a -2 slope, whereas the von Kármán spectrum attenuates with a $-5 / 3$ slope. A comparison of the two spectra is given in Fig. 10. An extended application of the discrete gust input, a positive one-minus-cosine shape immediately followed by a negative one-minus-cosine shape, is employed in the present analysis and is computed in the frequency-domain as

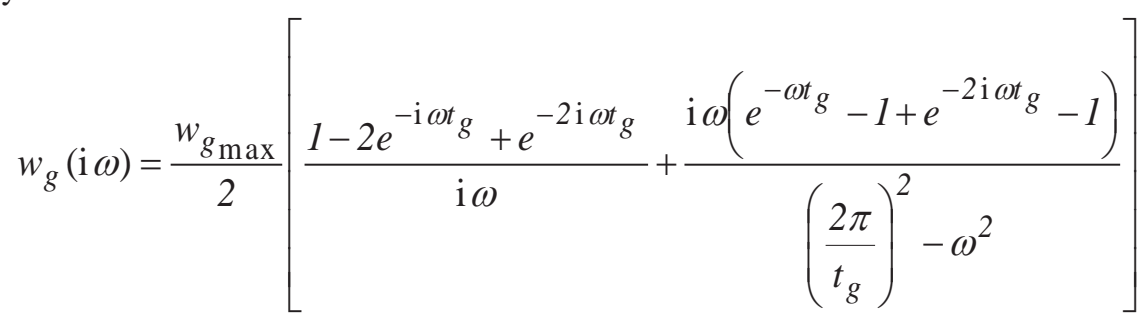

where

$$
t_{g}=\frac{l_{g} C_{w}}{V}
$$

and $c_{w}$ is the local chord of the wing strip.

The inverse Fourier transform of Eq. (14) yields a time-domain gust input (doublet one-minus-cosine gust) reflective of the example input illustrated in Fig. 11. The inclusion of an additional continuous frequency-domain input option and a doublet one-minus-cosine time-domain gust input enhances the gust response program by providing additional alternatives for analyzing aircraft responses to gusts.

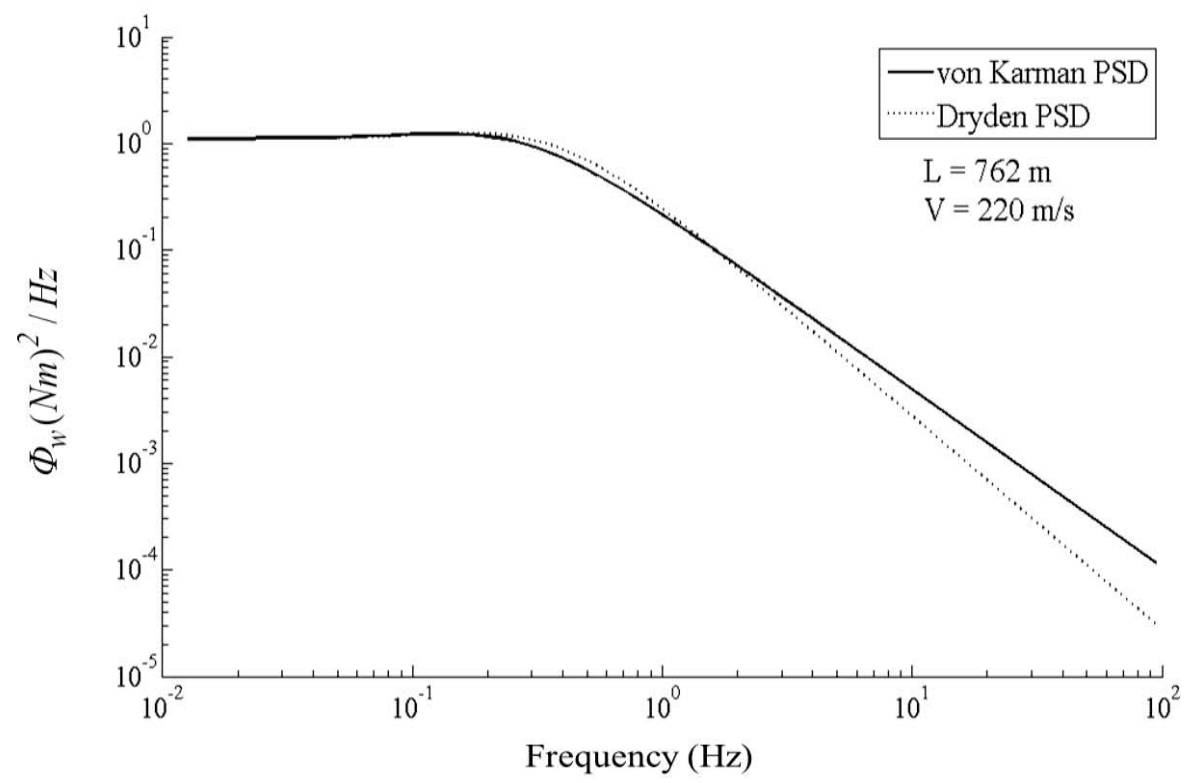

Figure 10. Comparison of Dryden and von Kármán Turbulence Spectra

11

American Institute of Aeronautics and Astronautics 


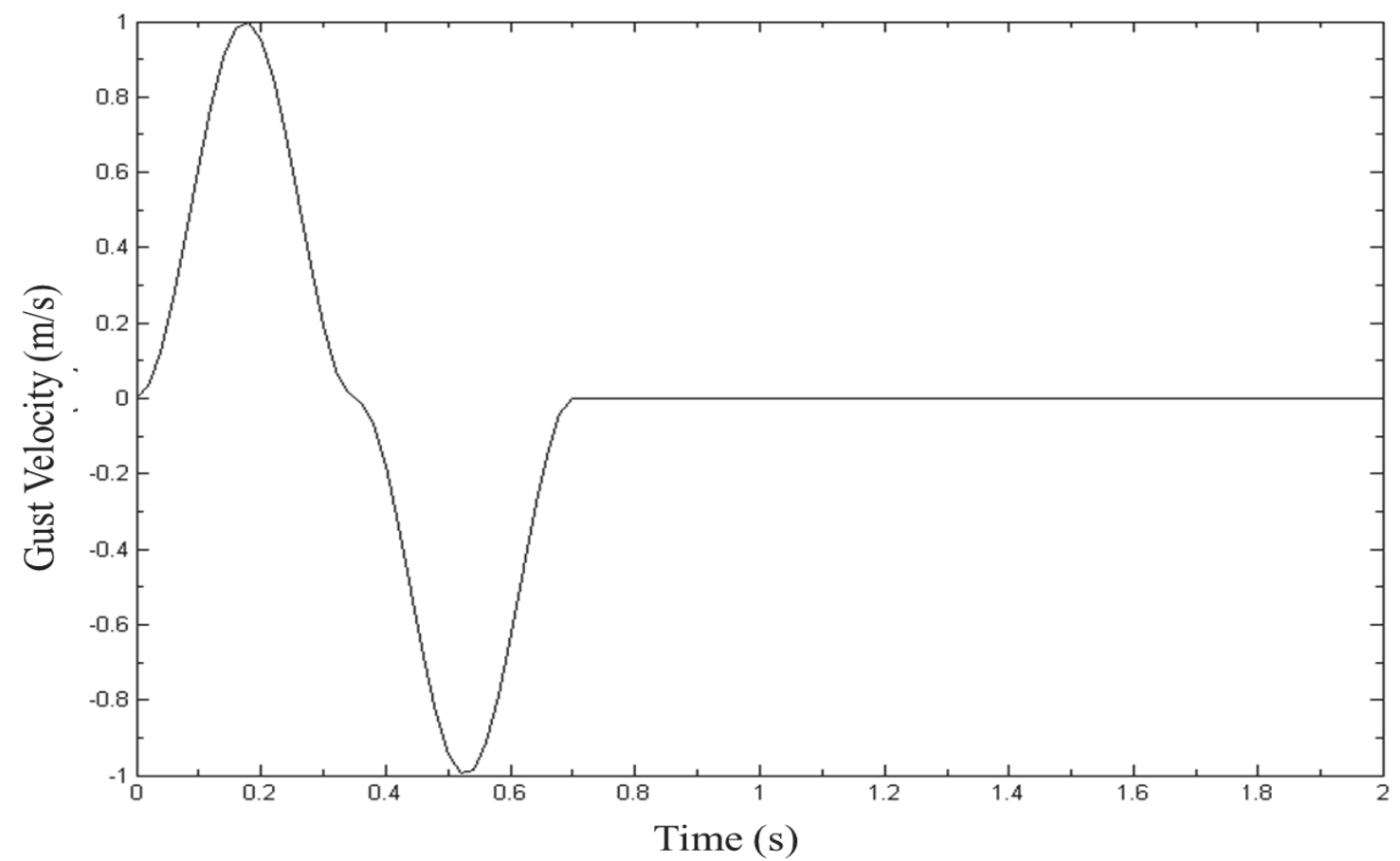

Figure 11. Doublet One-Minus-Cosine Gust Input

\section{Modification of Horizontal Tail Mode Shapes and Capability to Animate Total Vehicle Deformation Response}

In Ref. 2, the single-strip horizontal tail is restricted to be rigid and is given pitch and plunge mode shapes equal to unity. The connection between the fuselage and the horizontal tail remains straight. ${ }^{2}$ Given these restrictions, an animation of the total vehicle deformation response shows that the horizontal tail does not translate as a consequence of vehicle response in pitch and fuselage bending modes. In order to correct this response behavior, the pitch mode is defined to include the strips along the horizontal tail. Comparable to the modification of the horizontal tail pitch mode, a modified rear fuselage bending mode shape is applied to allow motion of the horizontal tail. In this modification, the horizontal tail is attached to the aft-most mass point along the fuselage.

Analysis of the total vehicle deformation response to a gust input with a visual application is particularly useful. Developed in this analysis is the capability to produce such an application through gust response animations. Animation of the total vehicle deformation response to a gust input requires expansion of the existing structural model to include the z-direction displacements at the corner points of each strip of the aerodynamic model. Additionally, given the modification to include a user-defined number of strips, the expanded structural model requires the capability to compute the total deformation for a variable structural model. An illustration of a newly defined structural model given for a twenty-strip swept and tapered configuration is presented in Fig. 12. A generalized sketch showing the locations of the corner points used in the rigid body mode shape computations is given in Fig. 13.

The $i^{\text {th }}$ mode shape is defined at corner point $j$ as follows. Mode shape 1 (plunge) is given as a vertical deflection expressed as

$$
\phi_{1}^{j}=1
$$

for each corner point $j$. For mode shape 2 (pitch), each corner point deflection is expressed as

$$
\phi_{2}^{j}=\left(x_{j}-x_{c g}\right) / x_{t}
$$

For mode shape 3 (rear fuselage bending), the first fuselage point is connected to the inboard trailing edge corner point of the aircraft wing. The $j^{\text {th }}$ fuselage point then deflects according to the third order polynomial given by

$$
\phi_{3}^{j}=\frac{1}{2}\left(\frac{x_{j}}{x_{t}}\right)^{2}\left(3-\left(\frac{x_{j}}{x_{t}}\right)\right)
$$




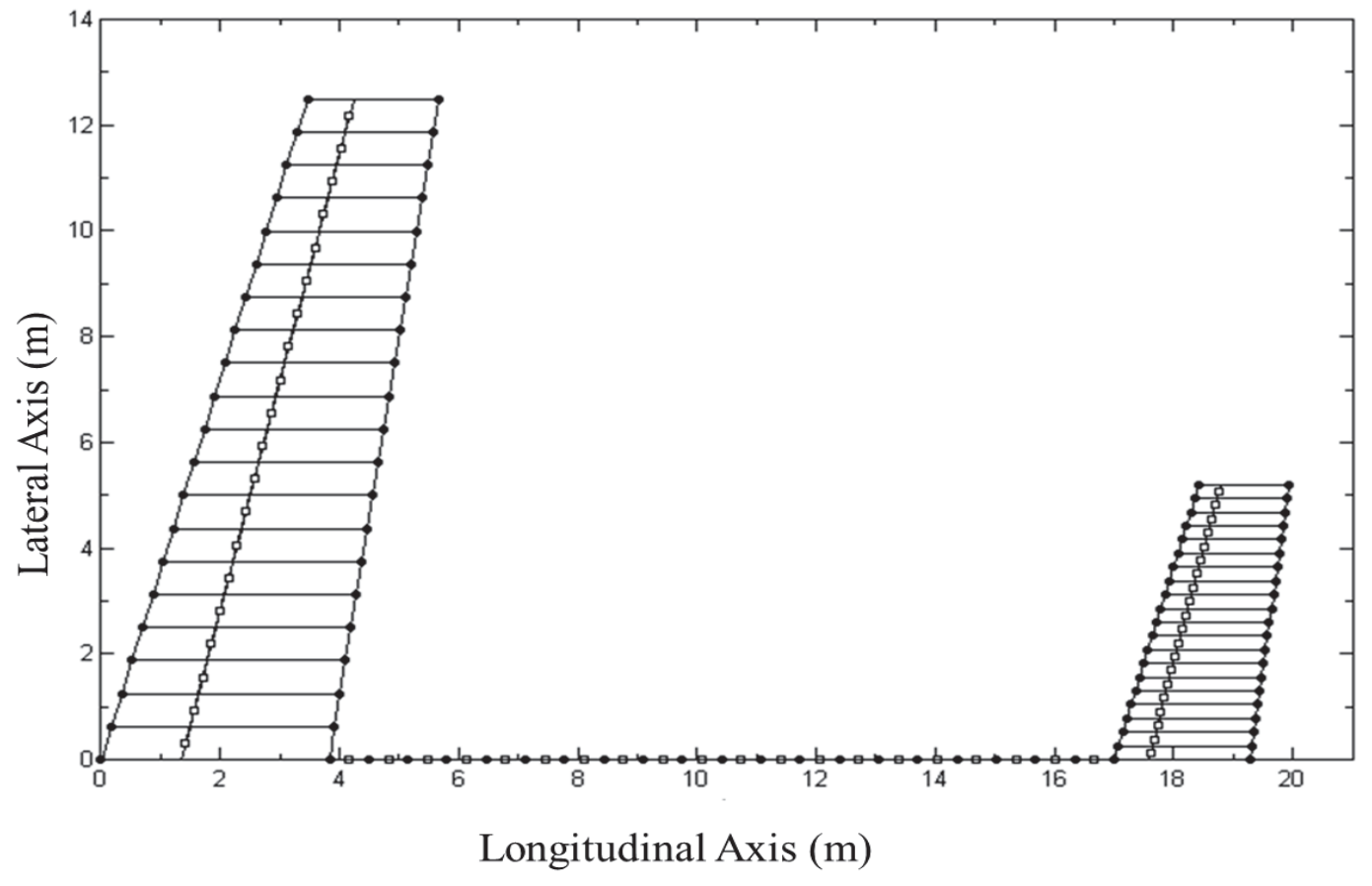

Figure 12. Revised Structural Model

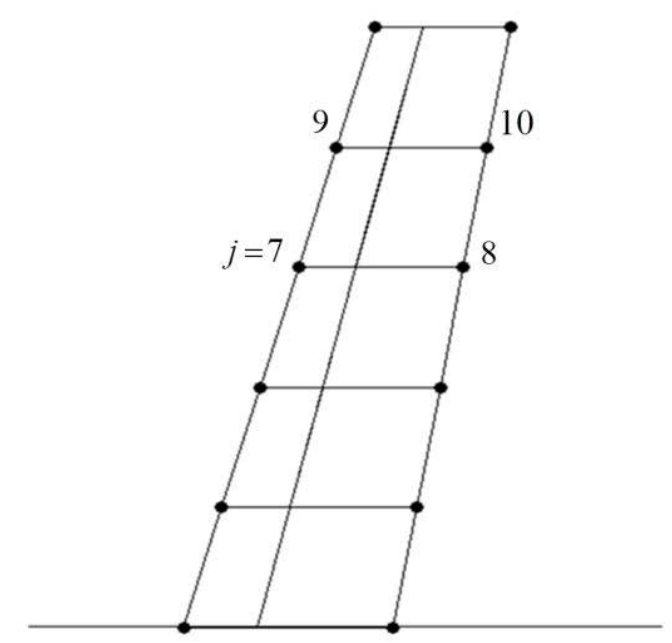

Figure 13. Sketch of Corner Point Locations

For the wing bending and torsion modes, the corner points are first projected onto the local y-axis coincident with the elastic axis and then computed as follows. For mode shape 4 (wing bending), the $j^{\text {th }}$ wing corner point deflects along the elastic axis according to the fourth order polynomial given as

$$
\phi_{4}^{j}=\frac{1}{3}\left(\left(1-\frac{2 y_{j}^{*}}{l_{w}}\right)^{4}-4\left(1-\frac{2 y_{j}^{*}}{l_{w}}\right)+3\right)
$$


where $y_{j}^{*}$ is the projection of the corner point, $y_{j}$, onto the local y-axis given by

$$
y_{j}^{*}=y_{j} \cos \Lambda
$$

and illustrated in Fig. 14. Lastly, for mode shape 5 (wing torsion), the $j^{\text {th }}$ wing corner point deflects along the local $\mathrm{y}$-axis according to the parabolic expression given as

$$
\phi_{5}^{j}=2 y_{j}^{*}-y_{j}^{* 2}
$$

where $y_{j}^{*}$ is the projection of the corner point $y_{j}$ onto the local y-axis as shown in Fig. 14

Screen shots of the capability to animate the total vehicle response to a gust are given in Fig. 15. In this depiction, the rigid body modes have been de-emphasized while the flexible modes have been exaggerated for visualization purposes. The horizontal tail has been omitted from this illustration. Frames are captured at $\mathrm{t}=0.02$ seconds, $\mathrm{t}=0.50$ seconds, and $\mathrm{t}=1$ second.

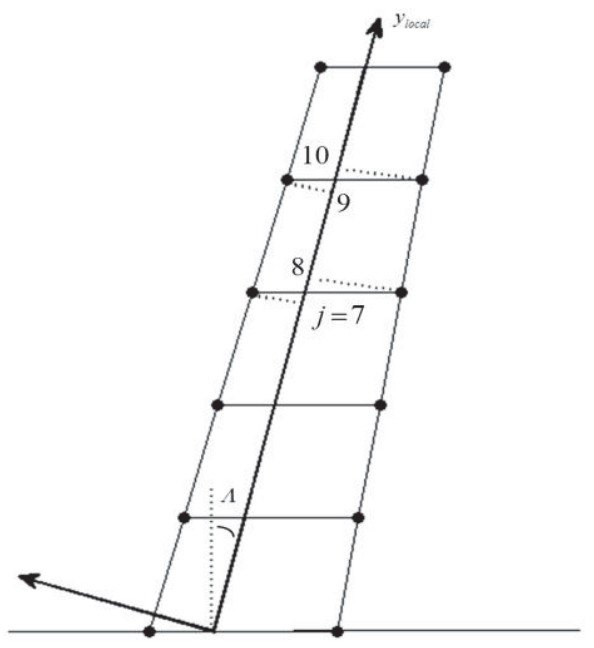

Figure 14. Sketch of Corner Point Projections

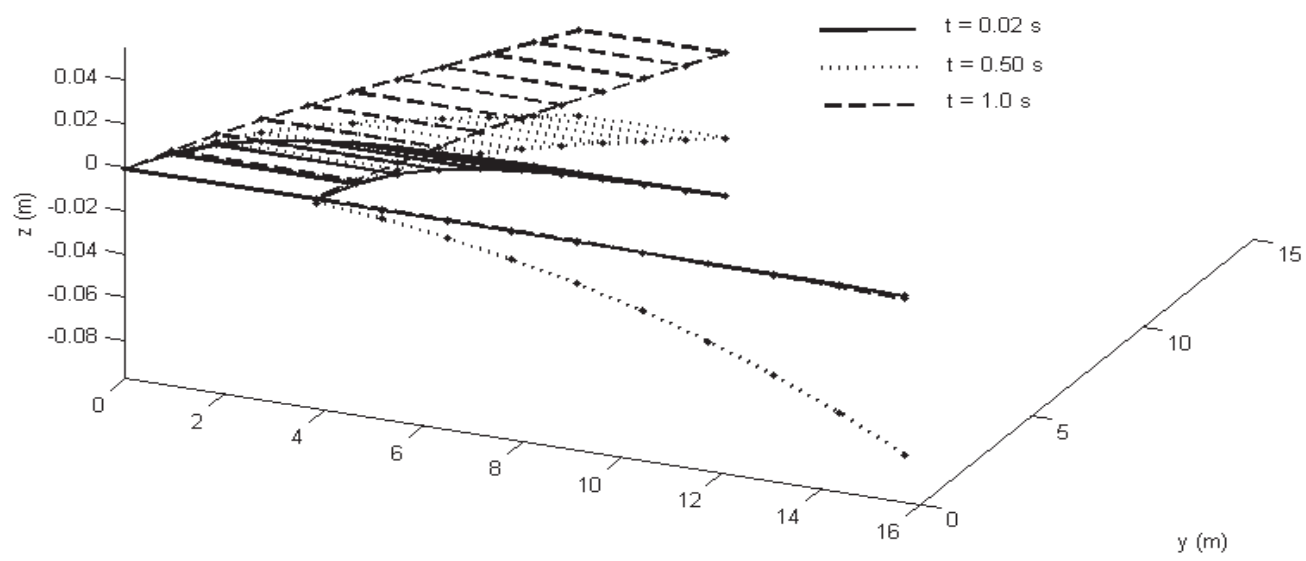

$x(m)$

Figure 15. Animation of Vehicle Deformation Response to Gust Input

American Institute of Aeronautics and Astronautics 


\section{E. Addition of Aircraft Wing and Horizontal Tail Control Surface Capability}

While the application of active controls is beyond the scope of this stage of research, the inclusion of a control surface capable of deflection is provided in the present analysis. Control surfaces are considered to be rigid and an infinitely stiff actuator is assumed. The implemented control surfaces are of user-defined span and chord and are positioned at user-defined wing and horizontal tail span locations. For computational simplification, this algorithm approximates the user-defined control surface position using a minimum difference approach so as to confine the inboard and outboard control surface boundaries to the boundary of the nearest strip. An illustration of a 20\%-chord wing control surface positioned with the outboard edge at $80 \%$ wing span and the inboard edge at $60 \%$ span for a ten-strip wing configuration is given in Fig. 16.

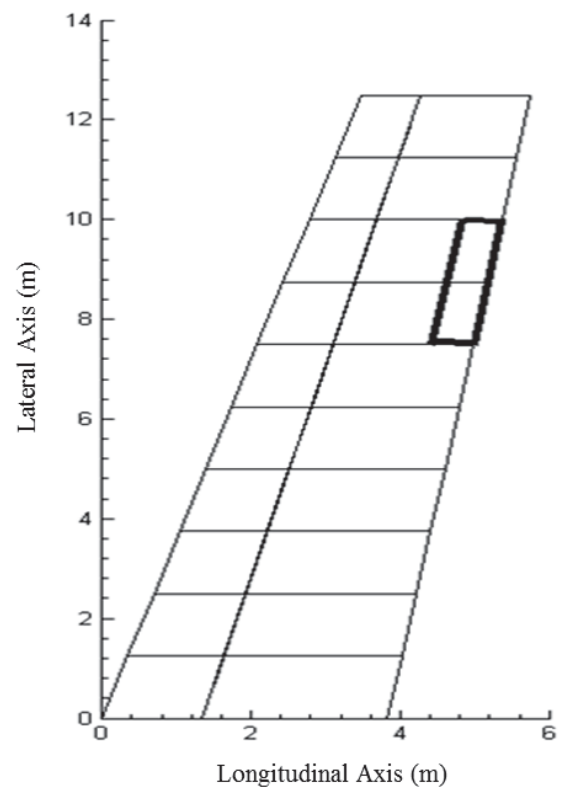

Figure 16. Wing Control Surface

Control surface deflection $\delta$ is defined to be positive trailing edge down and this input gives a z-deflection of the control surface point $i$, located on the trailing edge at the center of each control surface strip, expressed as

$$
z_{C S_{i}}=c_{C S_{i}} \tan \delta
$$

for $i=1,2, . . n_{c s}$ where $n_{c s}$ is the number of strips contained in the span of the control surface and $c_{c s_{i}}$ is the control surface chord. A positive control surface deflection contributes to an increase in coefficient of lift at the control surface. Due to the assumption of linearity, the principle of superposition applies; therefore, the total lift acting on a vehicle strip $i$ with a control surface deflection $\delta$ is computed as illustrated in Fig. 17.

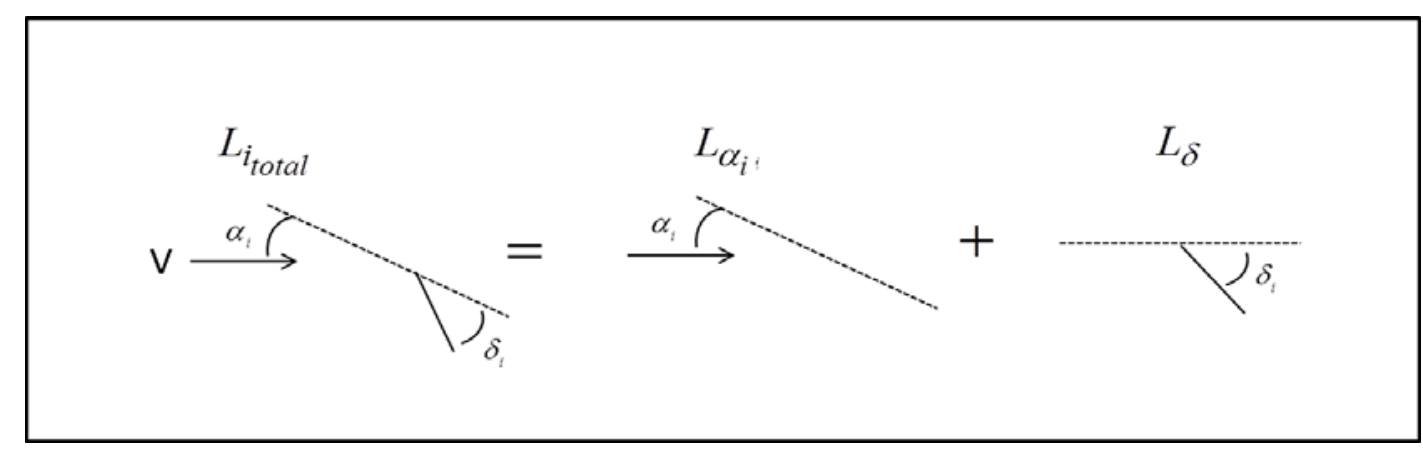

Figure 17. Total Lift per Strip Using Principle of Superposition

American Institute of Aeronautics and Astronautics 


\section{Results and Discussion}

A comparative evaluation is provided for analysis of the correlations and/or discrepancies between the revised gust load program and the original program. This comparative analysis serves as validation of proper implementation of these revisions. Test case scenarios used to illustrate the applications of the revisions are given in Table 2. Select results are discussed herein; however, all results can be found in Ref. 6.

Table 2. Test Case Scenarios

\begin{tabular}{|l|l|}
\hline$\underline{\text { Case Number }}$ & $\underline{\text { Test Case Scenario }}$ \\
\hline 1 & $\begin{array}{l}\text { Comparative Analysis of Load Responses due to One-Minus-Cosine Gust } \\
\text { Input }\end{array}$ \\
\hline 2 & Comparative Analysis of Load Responses due to von Kármán Turbulence \\
\hline 3 & Comparative Analysis of Load Responses due to Stochastic Gust Input \\
\hline 4 & $\begin{array}{l}\text { Variation of Aircraft Geometry: Inclusion of Horizontal Tail Sweep-Back } \\
\text { Angle }\end{array}$ \\
\hline 5 & $\begin{array}{l}\text { Variation of Aircraft Geometry: Inclusion of Aircraft Wing and Horizontal } \\
\text { Tail Taper }\end{array}$ \\
\hline 6 & Mass Properties: Variable Number of Mass Points \\
\hline 7 & Stiffness Properties: Linear EI and GJ Distributions \\
\hline 8 & Stiffness Properties: Cubic Spline Interpolation Method \\
\hline 9 & Extended Gust Input Applications: Dryden Turbulence Spectrum \\
\hline 10 & Extended Gust Input Applications: One-Minus-Cosine Gust Input \\
\hline 11 & Control Surface Capability: Aircraft Wing Control Surface \\
\hline 12 & Control Surface Capability: Horizontal Tail Control Surface \\
\hline 13 & $\begin{array}{l}\text { Animation of Total Vehicle Physical Deformation Response: Illustration of } \\
\text { Revised Horizontal Tail Mode Shape }\end{array}$ \\
\hline
\end{tabular}

For case number 1, a comparison of the time histories of the load responses obtained from Ref. 2 and the time histories of the load responses obtained from the modified program, given a discrete one-minus-cosine gust input, is shown in Fig. 18. Fig. 18 shows that the baseline case is not disrupted by the revisions.

For case number 2, a PSD comparison of each load response obtained from Ref. 2 and the modified program, given the von Kármán continuous turbulence input, is shown in Fig. 19. Again it is shown that the baseline case is not disrupted by the revisions.

For case number 5, at default flight conditions, the original structural configuration is implemented with the inclusion of aircraft wing and horizontal tail taper. A comparison of time responses for variation in taper ratio is shown in Fig. 20. For this example, both wing and horizontal tail taper ratios are varied simultaneously by holding wing and tail spans and root chords constant and varying only their respective tip chords. In this example no other quantities are varied, including wing and tail lift curve slopes, masses, and inertias. By varying taper ratio in this manner, the lifting surface area (wing or tail) is proportional to the quantity $(1+\lambda) / 2$, where $\lambda$ is taper ratio.

The peak responses from Fig. 20 were extracted and plotted as a function taper ratio. These results are in a form that is convenient for comparisons with results from independent checks. Independent checks are valuable because they help to validate the results of the present study. The Pratt formula provides an approximate independent check of the normal load factor peak responses. The Pratt formula ${ }^{1}$ estimates the normal load factor response of a vehicle to a unit one-minus-cosine gust, but assumes only vehicle plunging motion. This assumption results in a much simplified math model of the vehicle compared to that in the present analysis, but it is felt that the Pratt formula retains enough of the essential physics of the problem to be useful as an approximate independent check. When the normal load factor peak responses are plotted as a function of the quantity $(1+\lambda) / 2$, they are seen to be very nearly linear with respect to that parameter and therefore qualitatively agree with the results from the Pratt formula, thus providing an approximate independent check to the present analysis. 

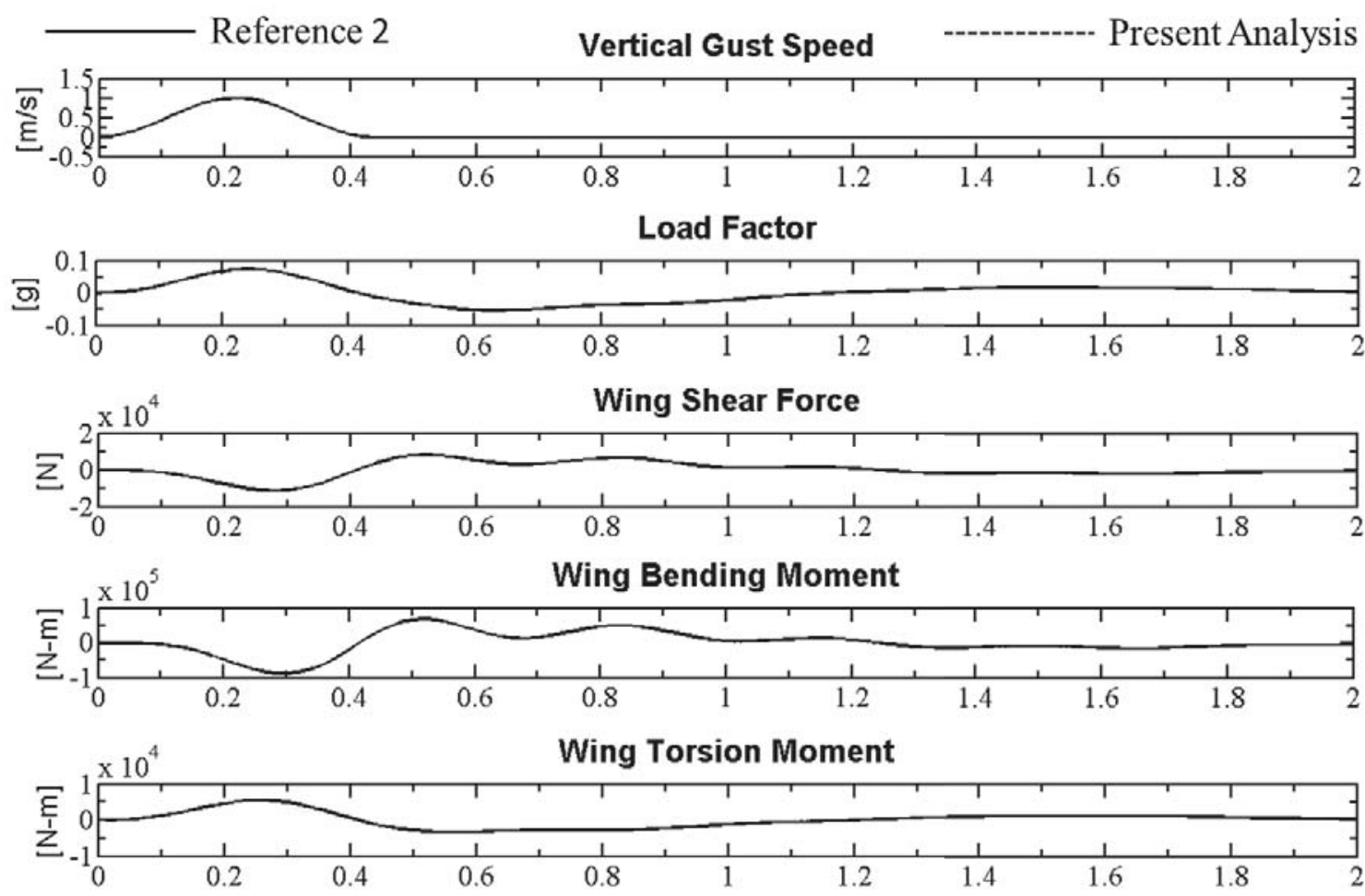

Tail Shear Force

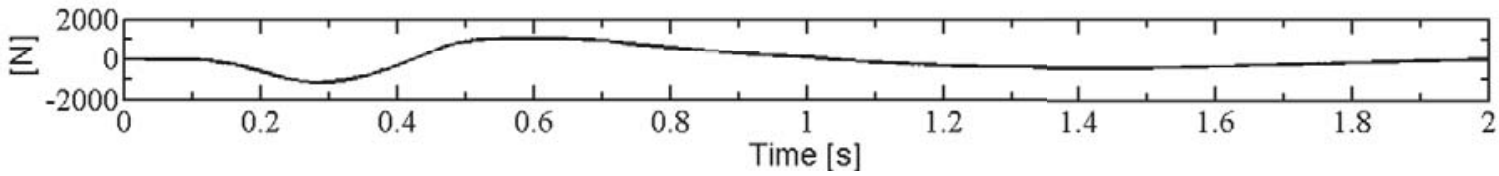

Figure 18. Comparison of Load Responses due to One-Minus-Cosine Gust Input
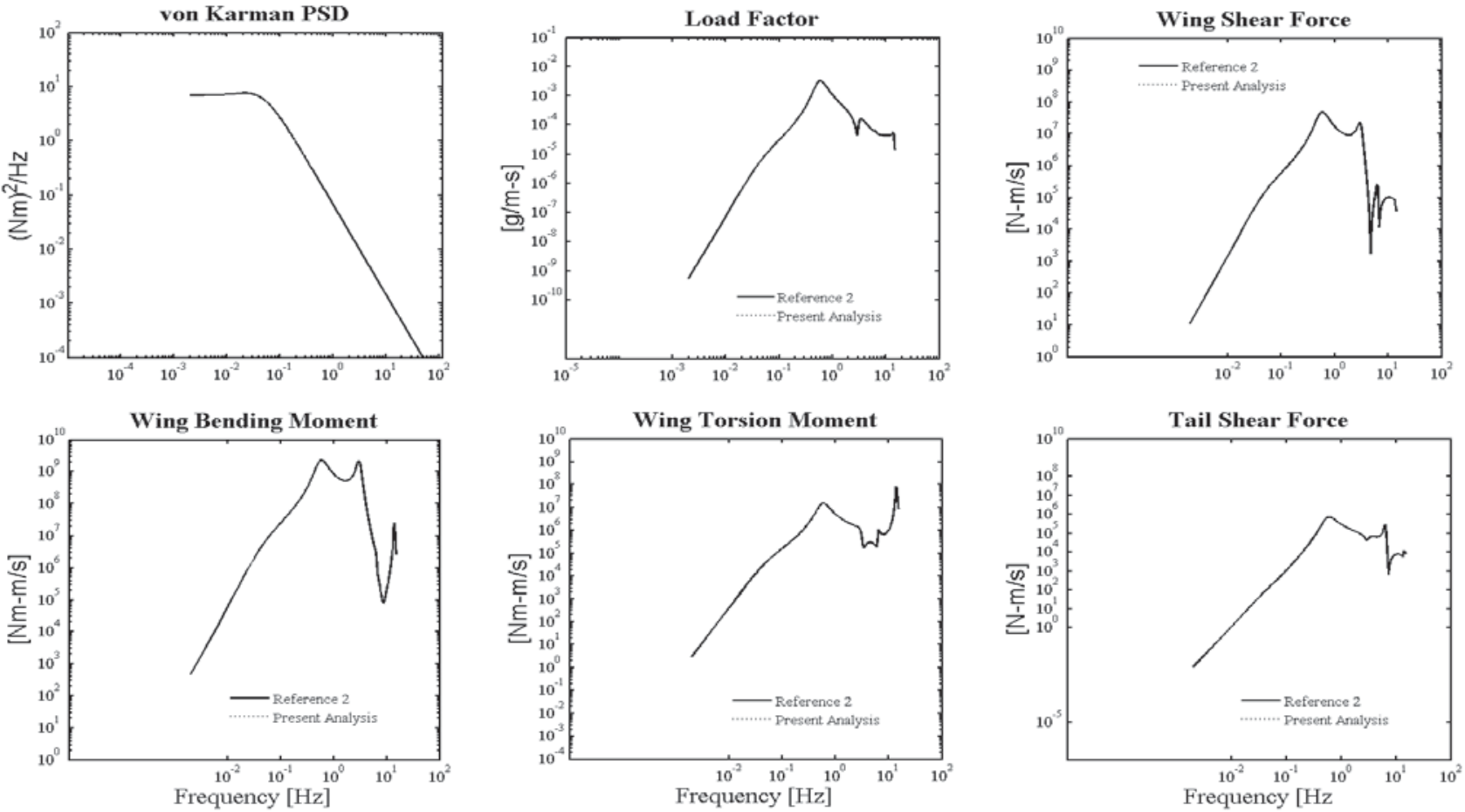

Figure 19. PSD Comparison of Load Responses due to von Kármán Turbulence

17

American Institute of Aeronautics and Astronautics 

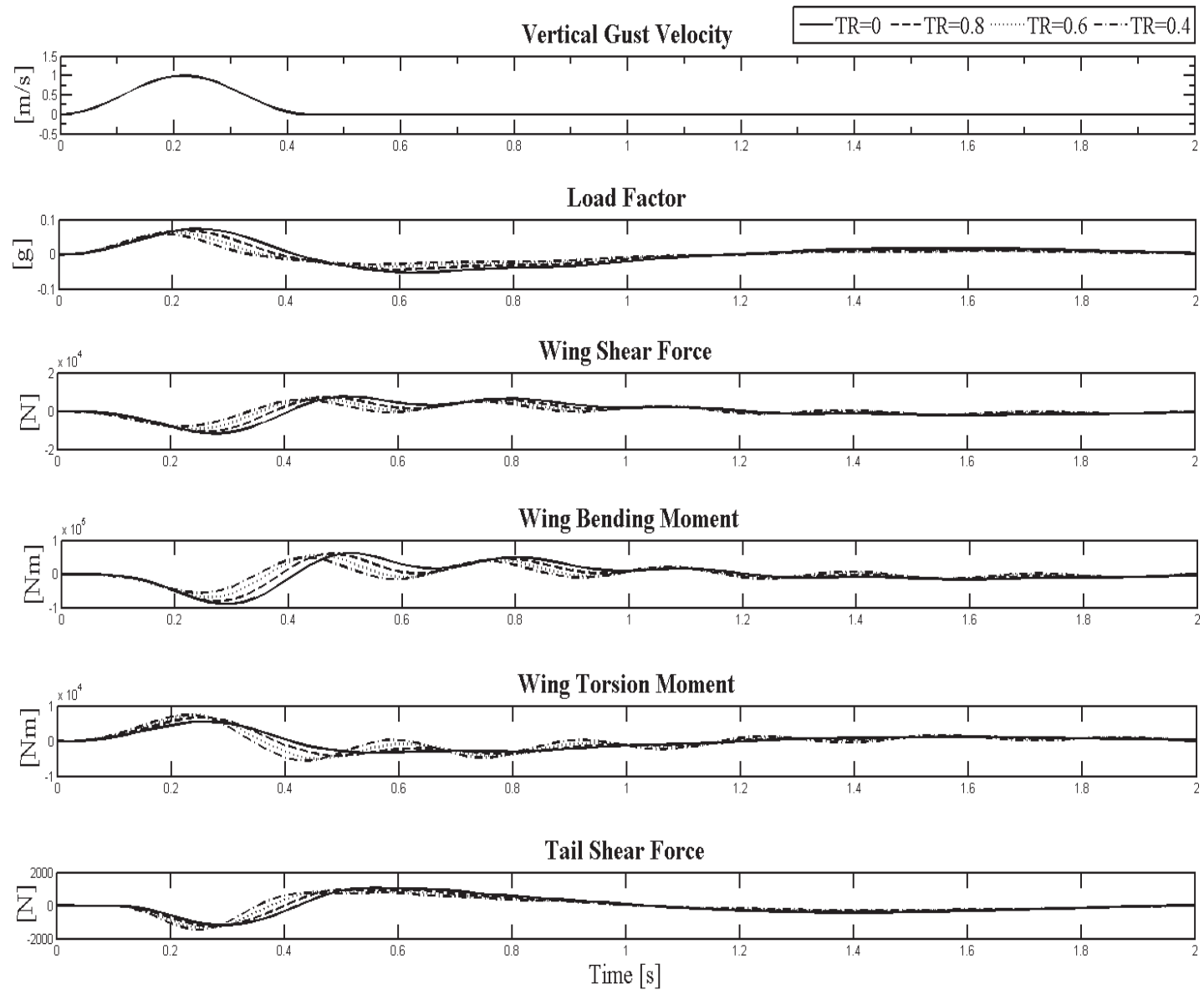

Figure 20. Comparison of Load Responses for Various Wing and Horizontal Tail Taper Ratios

For case number 9, the Dryden continuous turbulence spectrum is implemented. A comparison of load responses due to a Dryden input spectrum and a von Kármán input spectrum is conducted in order to analyze load response trends. The Dryden turbulence spectrum is given by Eq. (13). A comparison of the two turbulence spectra is provided in Fig. 10. As Fig. 10 shows, in the high-frequency region, the von Kármán PSD is always above the Dryden spectra; therefore, the values of the output loads spectra due to a von Kármán input are always higher than the corresponding values due to a Dryden spectrum input in this frequency region. On a logarithmic plot, the highfrequency asymptotes of the von Kármán spectrum and the Dryden spectrum have slopes of $-5 / 3$ and -2 , respectively. A comparison of the output PSDs for identical configurations due to each of the input turbulence spectra is given in Fig. 21. The original unswept, untapered aircraft configuration is implemented in this test case. For each of the outputs, the modulus squared of the frequency response function (FRF) is the same and, because the output spectrum is equal to the product of the input and the modulus squared of the FRF, any differences in the output PSDs are due to only the differences in the input spectra. Thus, input and output spectra in Figs. 10 and 21 are consistent. 

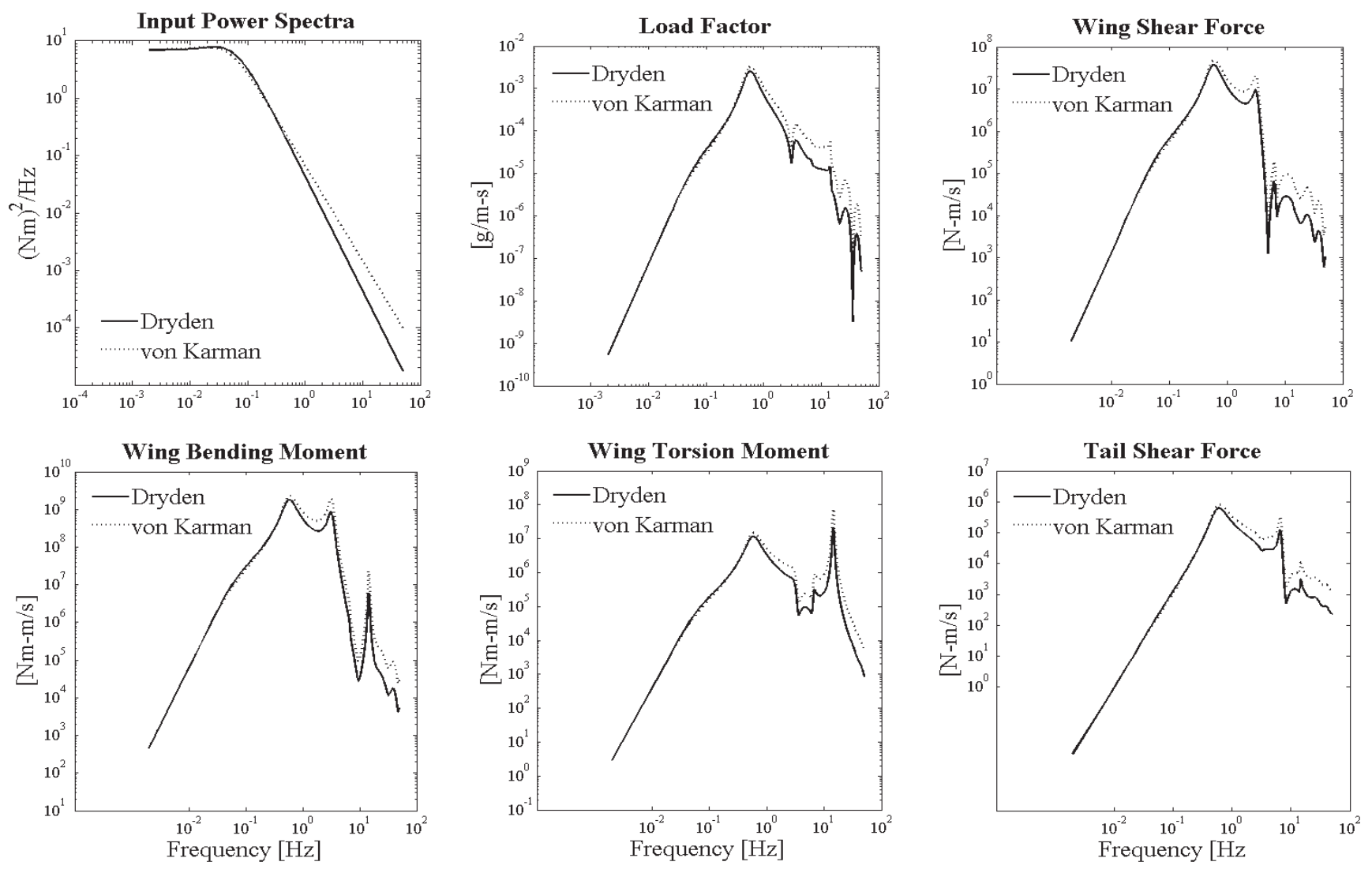

Figure 21. Output Load Comparison due to von Kármán and Dryden Inputs

\section{Concluding Remarks}

The following improvements and enhancements were successfully implemented, thereby furthering the cabilities presented in the original gust load analysis program: 1) aircraft wing and horizontal tail taper; 2) horizontal tail sweep; 3) variable number of strips; 4) Dryden turbulence spectrum; 5) doublet one-minus-cosine gust input; 6) control surfaces; 7) animation of total vehicle deformation response; and 8) modified horizontal tail mode shapes. Future efforts to implement active controls and to compare gust responses to NASTRAN solutions will further improve the versatility of this gust load analysis program.

\section{Acknowledgements}

The authors acknowledge Mr. Stanley Cole of the NASA Langley Aeroelasticity Branch and Drs. Robert Ash and Colin Britcher of the Old Dominion University Department of Mechanical and Aeroespace Engineering for their contributions to this work.

\section{References}

${ }^{1}$ Murrow, H., Pratt, K., and Houbolt, J., "NACA/NASA Research Related to Evolution of U.S. Gust Design Criteria," AIAA1989-1373, Proceedings of the AIAA Structures, Structural Dynamics, and Materials Conference, Mobile, Alabama, April, 1989.

${ }^{2}$ Vink, W. and de Jonge, J., "A MATLAB Program to Study Gust Loading on a Simple Aircraft Model," TP-97379-U, National Aerospace Laboratory, Amsterdam, The Netherlands, July, 1997.

${ }^{3}$ Meriam, J., Dynamics, John Wiley and Sons, New York, New York, 1971.

${ }^{4}$ Fung, Y., An Introduction to the Theory of Aeroelasticity, Dover Publications, New York, New York, 1969.

${ }^{5}$ Hoblit, F., Gust Loads on Aircraft: Concepts and Applications, American Institute of Aeronautics and Astronautics, Reston, Virginia, 1988.

${ }^{6}$ Funk, C., "Modification and Application of a Turbulence Response Analysis Method for Flexible Aircraft Configurations," M.S. Thesis, Department of Mechanical and Aerospace Engineering Dept., Old Dominion Univ., Norfolk, Virginia, 2012. 